\title{
Sylvio Back nas tensões entre cinema e estado: anos 1960-70
}

\author{
Sylvio Back in the tensions between cinema and state: \\ the 60's and 70's
}

\section{Rosane Kaminski*}

\section{RESUMO}

O texto situa o posicionamento do cineasta Sylvio Back frente às movimentações que marcaram a relação entre cinema e Estado nas décadas de 1960 e 1970. Naquele contexto era visível o desdobramento de um cinema brasileiro politizado e esteticamente "violento", cujos filmes de baixo orçamento e linguagem renovadora se impunham como forma de oposição ao cinema clássico e mais plenamente industrial. Ao mesmo tempo, ampliava-se o interesse do Estado pela produção cinematográfica em termos empresariais. Durante o regime militar, foram criados órgãos de premiação e fomento ao cinema defendendo a produção de filmes que reforçassem o estatuto industrial do cinema nacional, buscando o aumento de arrecadação nas bilheterias. Em meio a essa situação paradoxal, Sylvio Back estreou na direção de longas-metragens prometendo realizar filmes "sérios" e que se propusessem à comunicação com o público. Para avaliar a inserção desse cineasta nas tensões entre cinema e Estado, são confrontados os depoimentos e entrevistas publicados na imprensa da época e que atestaram publicamente as intenções do cineasta; algumas críticas sobre seus filmes; bem como os filmes de ficção produzidos por Back durante o regime militar, que consistem numa forma de posicionamento do autor perante as questões estéticas e políticas do seu tempo.

Palavras-chave: Cinema e história. Cinema brasileiro. Sylvio Back. Regime militar.

\section{ABSTRACT}

This paper discusses filmmaker Sylvio Back and the relationships between cinema and the State during Brazil's military regime in the 1960s and 1970s. Back then, Brazilian cinema was mainly political and aggressive. At the same time, the government was interested in the film industry, and created awards

\footnotetext{
*Rosane Kaminski é professora Adjunta da Universidade Federal do Paraná, atua como docente nos cursos de Graduação e Pós-Graduação em História. Autora da tese de doutorado "Poética da Angústia: história e ficção no cinema de Sylvio Back, 1960-70".
} 
and financing entities in order to increase national box office earnings. Sylvio Back then started to make films, saying that his intentions were to make "serious" movies, but that could be understood by their public. To analyze this filmmaker's insertion in the conflicts between cinema and the State, we used interviews and testimonies from Back himself that were published on the press at the time, and understood that his fiction movies were a form of positioning himself on his context's political and aesthetic matters.

Keywords: Movies and history. Brazilian cinema. Sylvio Back. Military regime.

\section{Um lugar para Sylvio Back no cinema brasileiro dos anos 1960}

O envolvimento de Sylvio Back com o cinema iniciou em Curitiba, na virada dos anos 1950-60, quando vários cineastas brasileiros iniciavam a sua integração nos debates culturais mais politizados. Desde fins da década de 1950, por meio da atuação como jornalista cultural, verifica-se a persistente atenção de Back ao que se processava no meio cultural e cinematográfico brasileiro. No início da década de 1960, suas primeiras experiências com curtas e médias metragens seriam um modo de pensar e preparar o seu primeiro longa-metragem de ficção, o Lance Maior, produzido e lançado em 1968. Do mesmo modo, suas experiências frente ao contexto extra-cinematográfico contribuíram para formar o repertório e o foco de preocupações sociais, políticas e existenciais abordadas em seus filmes.

Para iniciar este texto, cujo objetivo é situar o posicionamento de Back frente às movimentações que marcaram a relação do cinema com o Estado nas décadas de 1960 e 1970, é preciso ressaltar que a produção dos seus três primeiros longas-metragens de ficção e a sua inserção no cenário cinematográfico nacional aconteceriam dentro do arco temporal em que o Brasil esteve sob a égide do governo militar, instaurado após o golpe de Estado ocorrido em 1964 e prolongado até meados da década de oitenta.

Como se sabe, o governo militar tomou uma série de medidas para legitimar e preservar o poder no decorrer daqueles anos, indo desde a promulgação dos diversos Atos Institucionais que possibilitaram ao executivo cassar mandatos e suspender direitos políticos, até atitudes mais extremas, como as prisões e a tortura, visando reprimir quaisquer ações consideradas subversivas. O teor de efervescência social, política e cultural que havia marcado o "tempo nacional" dos primeiros anos da década de 1960, sofreu abrupta interrupção com o golpe de 1964 e o autoritarismo de direita. Ao mesmo tempo, se investia na política de crescimento econômico-industrial. Nesse contexto, as relações entre produtores de cultura e o Estado também passaram por uma série de rearticulações. As medidas desenvolvimentistas adotadas pelo governo militar exerceram forte impacto no 
meio cultural, sobretudo com a ampliação dos meios de comunicação de massa, configurando um fenômeno de reorganização e fortalecimento da indústria cultural nacional que teria repercussões também no cinema brasileiro. ${ }^{1}$

Uma das primeiras diretivas do governo federal em relação ao cinema foi a criação do Instituto Nacional de Cinema (INC), em fins de 1966, sob forma de autarquia subordinada ao MEC. Apesar de ser apresentado como "órgão neutro", o INC era capitaneado por um grupo de críticos e cineastas avessos às propostas cinemanovistas - com Flávio Tambellini na direção, apoiado apoiado pelos chamados "universalistas" Moniz Viana, Ely Azeredo e Rubem Biáfora, entre outros -, conforme aponta Ortiz Ramos (1983, p. 51-53). ${ }^{2}$ As propostas do INC seguiam as balizas do "desenvolvimento cinematográfico" que vinham das discussões do GEIC e do GEICINE ${ }^{3}$, nos quais Tambellini também tivera papel de destaque. Defendia-se um cinema nacional de dimensões industriais, realizado em coprodução com empresas estrangeiras, e com medidas modestas de limitação da entrada do filme estrangeiro.

Segundo Ortiz Ramos (1983, p. 59), a marginalização do cinema novo, a maior força ao segmento afeito ao "cinema universal", e a decisão do Estado em intervir na questão cultural, são fatores que se entrelaçaram na origem do INC. Este foi um órgão de regulamentação fiscal e premiação antes de ser uma agência de financiamento. De qualquer modo, com os recursos oriundos dos impostos sobre filmes estrangeiros, a produção nacional cresceu significativamente. Ainda que o grupo dos universalistas tenha sido privilegiado com esse sistema, no que diz respeito ao número de filmes realizados, os cinemanovistas também se beneficiaram desses capitais, como também muitos diretores que não se ligavam a esses

\footnotetext{
${ }^{1}$ Esse fenômeno é apontado e discutido pelos sociólogos Sérgio Miceli (1994, p. 47-49) Sergio Caparelli (1980, p. 9-33), Renato Ortiz (1988, p. 113-148) e Marcelo Ridenti (2000). Quanto às relações estabelecidas entre cinema brasileiro e governo militar, suas nuances e contradições foram trabalhadas de modo aprofundado por Ortiz Ramos (1983).

${ }^{2}$ A partir das primeiras discussões em torno das possibilidades de desenvolvimento do cinema nacional ocorridas em São Paulo ainda nos anos cinquenta, José Mário Ortiz Ramos esquematiza dois eixos que se desdobrariam, daí até a década seguinte, em duas posturas distintas: uma nacionalista e outra universalista. Desde 1952, por exemplo, Nelson Pereira dos Santos mostrou-se a favor de uma orientação nacionalista no conteúdo dos filmes como estratégia para conquistar o mercado interno, enquanto outros pensavam em medidas no campo da legislação ou financiamento econômico, reivindicando, para isso, uma aliança entre burguesia nacional, Estado e grupos produtores de cultura. Além de Nelson Pereira, também Rodolfo Nanni e Alex Viany apresentavam, desde então, certas ideias relativas a um cinema nacional independente, ideias estas que seriam retomadas no começo da década de 1960 por Glauber Rocha e também por Maurice Capovilla. Noutra vertente, entretanto, conhecida como universalista, outros estavam mais preocupados em pensar um modo de fortalecer o cinema brasileiro a partir da valorização desta atividade por parte do governo como uma atividade com potencialidade de gerar divisas. Era o que defendiam, por exemplo, Flávio Tambellini e Cavalheiro Lima. A esta postura, associam-se cineastas como Walter Hugo Khouri e Rubem Biáfora. (RAMOS, 1983, p.15-49). Está correta está forma de citação? poderia por faor, nos indicar em que norma da ABN esta forma de citação que está em amarelo é indicada?

${ }^{3}$ Em 1956 havia sido instituído o Grupo de Estudos da Indústria Cinematográfica (GEIC), subordinado ao Ministério da Educação, e em 1961 foi criado o Grupo Executivo da Indústria Cinematográfica (GEICINE). Este era, no início, também vinculado ao MEC, mas a partir de 1963 ficaria sob jurisdição do Ministério da Indústria e Comércio (RAMOS, 1983, p.29).
} 
dois grupos (RAMOS, 1983,p. 60-62). ${ }^{4}$

Mas foi em fins de 1969, a partir do surgimento da Empresa Brasileira de Filmes S/A (Embrafilme), que "a atividade cinematográfica teve assegurada a sua mais eficiente expressão dentro do aparato do Estado" (AMÂNCIO, 2000, p. 123). Na prática, a ação da Embrafilme consistiu inicialmente em auxiliar ao INC, que continuava com suas ações de regulamentação e consagração. Nesse quadro, o governo decidia assumir uma visão empresarial sobre o cinema brasileiro fortalecendo o seu aspecto industrial.

Sylvio Back, na ocasião, não era ligado a nenhum desses grupos, mas logo que o Lance Maior estreou nacionalmente, em 1968, tornou-se visível uma "simpatia" dos universalistas pelo seu trabalho, especialmente através da crítica. Ely Azeredo e Rubem Biáfora, próximos a Tambellini, foram extremamente receptivos com o Lance Maior, o primeiro longa-metragem de Back e que trazia para o cenário nacional o "cinema paranaense", num projeto que, segundo Azeredo (1968a), "firmou suas raízes curitibanas e foi inteiramente criado e planificado por entusiastas locais". Noutra matéria, ele se referia a Lance como "um dos filmes brasileiros mais interessantes da safra corrente" (AZEREDO, 1968b). Biáfora (1969) chegou a afirmar que era "seguramente a mais legítima, consciente e sincera fita engajada de toda a conturbada trajetória do moderno cinema nacional".

Back afirma que não os conhecia pessoalmente naquele momento, e que só viria a conhecê-los nos anos setenta, em contatos sem muita profundidade. Sobre o Biáfora, diz que conversaram algumas vezes e falaram sobre as suas preferências cinematográficas, mas nunca chegaram a ser amigos. E quanto ao Ely Azeredo, Back (2007) assevera que jamais tiveram uma conversa longa, e que

quando 'Lance Maior' estreou no Rio de Janeiro, Ely escreveu duas críticas ao filme, [...] reconhecendo que o filme ia na contramão do que à época era considerado uma espécie de 'padrão estético', os filmes do Cinema Novo. Fiz um desconto pois, acho, Ely se aproveitou de suas inimizades (mútuas) com alguns diretores do CN e 'exagerou', acho eu, tanto nos prós e nos contras a respeito de 'Lance Maior'.

Entre 1968 e 1969 Ely Azeredo era o Editor-Geral da revista Filme Cultura, publicada pelo INC, e em novembro daquele ano saía lá a sinopse do primeiro filme de Back (Filme Cultura $\mathrm{n}^{0} 11,1968$, p. 57$) \cdot{ }^{5}$ No ano seguinte, a mesma revista editava uma matéria sobre Lance,

\footnotetext{
${ }^{4}$ Do grupo dos universalistas, por exemplo, seriam produzidos com os recursos oriundos da retenção do imposto de filmes estrangeiros, somente no ano de 1968: As Amorosas, de Khoury; O quarto, de Rubem Biáfora; e Até que o casamento nos separe, do próprio Tambellini. Quanto aos cinemanovistas, nos anos que se seguiram vários deles se beneficiaram da intervenção do INC para a produção de filmes. Merecem ser citados, entre outros: Os herdeiros (1969), de Cacá Diegues; Macunaíma (1969), de Joaquim Pedro de Andrade; e Como era gostoso o meu francês (1970), de Nelson Pereira dos Santos, que havia sido ferrenho opositor do INC.

${ }^{5}$ A revista Filme Cultura existia desde 1966, quando da criação do INC, e permaneceu vinculada a este órgão até ocorrer a sua extinção, em 1975, quando então a revista passou a ser editada pela Embrafilme.
} 
afirmando que com este filme

o Paraná rompe as barreiras de uma cinematografia tímida e provinciana, lançando-se satisfatoriamente no panorama nacional. [...] Lance Maior, embora não represente nenhuma inovação no cinema brasileiro, constitui o grande salto do cinema do Estado. (DIKOFF, 1969, p. 30-31).

Não se pode negar que essas intervenções tenham colaborado na definição de um "lugar" para o novo cineasta na trama de relações e embates que se processavam naquele meio profissional. E como esta trama é sempre movediça, tal "lugar" não ficaria solidificado. Tanto as características do contexto brasileiro quanto os interesses pessoais e profissionais do cineasta sofreriam modificações importantes nos dez anos seguintes, até que as repercussões em torno do lançamento de Aleluia, Gretchen!, em 1976, ampliassem a projeção de Back no meio cinematográfico. Inclusive, a produção de cada um dos três filmes aqui considerados corresponde a um momento peculiar dentro do arco temporal do regime militar.

A divisão do regime militar em três "fases", conforme proposta por Dreifuss e Dulci (1983), auxilia a perceber estas diferenças. Segundo esses autores, a primeira fase do regime corresponde ao período entre 1964 e 1968, com grande enfrentamento entre as diversas tendências políticas dos militares, e com as estratégias de legitimação do novo regime político. Nesse tempo, situa-se a produção e a estréia do Lance Maior. A segunda fase vai de 1968 a 1974, onde se consolida, pela linha dura, "o processo revolucionário permanente". Em tal contexto, Back realizou A Guerra dos Pelados, e também preparou, aos poucos, o projeto de seu terceiro filme. Finalmente, a terceira e última fase diz respeito aos anos que vão de 1974 à revogação do AI-5 (dezembro de 1978), com o período longo e tumultuado da distensão ou descompressão, caracterizado como lento e gradativo "processo de abertura política". É quando Aleluia, Gretchen! sai do papel, filmado em 1975, lançado em 1976 e consagrado como um dos melhores filmes nacionais em 1977.

Vejamos, portanto, de que modo o cineasta posicionou-se frente ao regime, por meio dos seus filmes, em cada um desses momentos.

\section{Os três primeiros filmes ficcionais de Sylvio Back e seu contexto de produção.}

Desde antes de produzir seu primeiro longa-metragem, Back se colocava como defensor de um cinema comunicativo, que falasse de temas "sérios" por meio de uma linguagem 
compreensível. Isso ocorreu num tempo em que a "política de atingir o público" era um dado forte, logo após a experiência de afastamento do público causada por um cinema de propostas estéticas eruditas, que resultaram, segundo Contier, num "cinema hermético, difícil" (CONTIER, 1979).

Lance Maior foi idealizado e filmado num tempo marcado pelas movimentações sociais, protestos de rua contra o regime ao longo de 1968, e também enquanto os militares providenciavam as medidas de legitimação e prolongamento de sua gestão federal. Finalizado, Lance chegou às telas antes ainda da oficialização do AI-5 (de 13 de dezembro), ou seja, antes de iniciar a fase mais dura do governo militar.

Back não se envolveu diretamente com os movimentos de rua que protestavam contra o regime ao longo de 1968, mas participava, desde 1967, da Ação Popular (AP). Essa organização, em Curitiba, constituía-se de um núcleo formado por duas bases sociais distintas: alguns estudantes e um grupo independente de esquerda, composto por intelectuais e profissionais liberais, aí incluindo Back. Apesar desse envolvimento político do cineasta e do momento de agitações sociais, o filme Lance Maior não trata diretamente de assuntos políticos. Através de uma estrutura narrativa simples, o filme de Sylvio Back conta a história de um círculo amoroso envolvendo três jovens que vivem em Curitiba na década de sessenta. Todos eles veem-se frustrados ao final do filme, pois nenhum consegue atingir os seus objetivos que parecem mesquinhos, individualistas, vazios, ou pautados no arrivismo. $O$ filme transparece, ao final, como uma denúncia, um desabafo sobre a rigidez atroz da estrutura social. Desse modo, se contrapõe às utopias revolucionárias que moviam os grupos de esquerda, e com os quais o próprio cineasta se envolveu.

Muito embora os vínculos do seu primeiro filme com a participação na AP sejam muito frágeis, alguns anos mais tarde ele traria a público o dilaceramento pelo qual passava, quando precisou escolher (aparentemente por imposição) entre fazer arte ou fazer política, e justificaria a sua opção: 
coisa inútil!". Cheguei a participar de inúmeras reuniões onde era obrigado a fazer a "autocrítica" de que estava melando o processo, que eu fazia algo "inútil". Naquele momento foi que decidi que seria um "inútil" até o fim da vida. Porque a poesia é uma coisa inútil, o cinema, idem, o imaginário, idem. A vida é uma coisa inútil. Mas, inútil, naquele sentido de que é a única coisa pela qual vale a pena se arriscar. O poder não vale a pena (BACK, 1988)

Estas palavras de Back são significativas, se pensadas num contexto em que se "exigia" das pessoas uma definição política e atitudes condizentes com tal definição, pois a trama de relações e os interesses em jogo, nesse tipo de opção, eram complexos. Conforme o conhecido texto que Roberto Schwarz escreveu entre 1969-70 para um público francês Cultura e política: 1964-69 -, apesar da vigência de uma ditadura de direita no Brasil, o meio cultural nacional perseveraria na busca de identificação com as ideias e grupos de esquerda. Mas as nuances dessa tendência à esquerda devem ser ponderadas caso a caso.

O segundo filme de Back, $A$ Guerra dos Pelados, toma um rumo mais enfático e dramático nessa questão das opções políticas. Trata-se de um filme histórico sobre um movimento armado ocorrido no Sul do Brasil entre 1912-1916, em que o mote central é a disputa pela terra. Representa, no tempo diegético, um visão crítica sobre o Movimento do Contestado e sobre o massacre sofrido pelos agricultores posseiros, num enfrentamento com o exército federal. Ao mesmo tempo, pode ser interpretado como uma alegoria frente ao regime militar, representando os ideais defendidos por grupos resistentes e a desigualdade de forças no enfrentamento desses ao poder militar. No final, o filme representa a inutilidade da resistência pela força das armas, o que parece coincidir com o desabafo pessoal de Back citado acima.

Esse segundo filme foi produzido em 1970, durante o tempo em que Emílio Garrastazu Médici ocupava o poder executivo federal, ou seja, o período mais violento da ditadura, e conhecido por sua dupla face: de um lado, o milagre econômico brasileiro (impulsionado grandemente pelo crescimento do investimento de capital estrangeiro), de outro, a repressão política que se intensificava, justificando o rótulo de anos de chumbo. A ação ideológica do Estado para com o cinema, no período entre 1969-74, estabelecia uma articulação entre uma produção de caráter comercial, que era o seu eixo principal, e a produção cultural, que privilegiava o filme "histórico" ou "literário" e servia de anteparo às críticas feitas à Embrafilme (BERNARDET, 1979, p. 53-54).

A criação da Empresa Brasileira de Filmes S/A (Embrafilme) havia ocorrido num momento de transição de governo, logo após a morte do presidente Marechal Costa e Silva e ainda antes de Médici assumir o governo, por meio do Decreto Lei $\mathbf{n}^{\circ} 862$, de 12 de setembro de 1969. Estava em plena vigência o Ato Institucional $n^{\circ} 5$, com os poderes econômicos concentrados nas mãos do governo federal, em detrimento dos governos estaduais e municipais. Nesse quadro, o governo decidia assumir uma visão empresarial sobre o cinema 
brasileiro fortalecendo o seu aspecto industrial.

Coerente com o discurso tecnocrático assumido pelos militares, a Embrafilme, vinculada ao Departamento de Assuntos Culturais do MEC, passou a ser apresentada como meramente técnica, neutra, e empenhada na defesa de um "abstrato bem comum". Com esse discurso, e dona de uma ação centralizadora, a nova empresa estatal seria, a princípio, alvo de críticas, tanto por parte dos cinemanovistas e cineastas de esquerda, quanto da direita (RAMOS, 1983, p.89-91). Aos poucos, porém, arregimentaria para os seus quadros até mesmo alguns dos agentes mais representativos do cinema novo, especialmente depois que o Ministro da Educação Jarbas Passarinho passou a defender um "nacionalismo cultural", tomando para o Estado um discurso que havia sido da esquerda na década anterior (RAMOS, 198, p.130-131). Todavia, se nos anos sessenta a questão nacional havia sido pensada em termos de aliança de classes, ou de um "todo nacional" que se opusesse ao domínio do capital estrangeiro, já em 1970, sob um governo de extrema direita, o resgate do "nacionalismo" se resumia ao âmbito cultural, uma vez que no plano econômico se privilegiava a internacionalização.

Esse projeto cultural ligado ao cinema, no entanto, vinha acoplado à iniciativa explícita do governo de implantar uma indústria cinematográfica que ocupasse o mercado fílmico. Deste modo, a ação ideológica do Estado para com o cinema, no período entre 1969-74, acabou estabelecendo uma articulação entre uma produção de caráter comercial, que era o seu eixo principal, e a produção cultural, que privilegiava o filme "histórico" ou "literário" e servia de anteparo às críticas feitas à Embrafilme (BERNARDET, 1979, p. 53-54).

Na prática, a ação da Embrafilme consistiu inicialmente em auxiliar ao INC que, nesse meio tempo, continuava com suas ações de regulamentação e consagração. Em fins de 1970, a revista Filme Cultura mencionava a produção de $A$ Guerra dos Pelados, de Back, numa entrevista realizada com o cineasta quando ele trabalhava na montagem do filme. Mas apesar da participação da revista do INC na divulgação do filme de Back, não houve intermediação financeira deste órgão na sua produção. A Guerra dos Pelados foi parcialmente financiado pelo Banco Regional de Desenvolvimento do Extremo-Sul, e produzido em parceria por Sylvio Back e pelos paulistas A.P. Galante e Alfredo Palácios, os mesmos que já haviam apostado no Lance Maior. Como se pode observar, o tempo de produção de $A$ Guerra dos Pelados coincidiu com os primeiros e incipientes meses da Embrafilme, antes mesmo dos pronunciamentos de Jarbas Passarinho sobre a importância dos filmes "históricos" e "literários". Tais pronunciamentos seriam noticiados no segundo semestre de 1970. Mas o Prêmio de Qualidade que o INC concedeu ao filme de Back em 1971 pode ser considerado, de certa forma, um benefício que o cineasta obteve diante dessa nova política cultural. Como resultado, um paradoxo: o mesmo filme que abordava criticamente temas urgentes - como a guerrilha camponesa e a repressão - era premiado por um órgão que pertencia ao Estado 
repressor. Contudo, o fato de ter adaptado um romance, ${ }^{6}$ além da roupagem "histórica" com que os temas estavam envoltos, enquadrava o filme nos requisitos que o MEC colocava como louváveis. Note-se, ainda, que o Júri Nacional de Cinema convocado para conceder os prêmios do INC naquele ano agrupava, além de Ely Azeredo e Rubem Biáfora, outros críticos que já haviam se manifestado acerca das obras de Sylvio Back: Rubens Ewald Filho, Luiz Alípio de Barros, Fernando Ferreira, Valério Andrade e Alberto Shatowsky. ${ }^{7}$

Mas A Guerra dos Pelados coincidiu, também, com a ascensão dos filmes de fácil aceitação. O filme Roberto Carlos a $300 \mathrm{~km}$ por hora (de Roberto Farias), por exemplo, teve a maior arrecadação do ano de 1971, no mesmo ano em que $A$ Guerra dos Pelados entrava em exibição nas salas de cinema de Curitiba, São Paulo e Rio de Janeiro, e vivenciava o fracasso de bilheteria.

Apesar de ter sido relativamente bem comentado pela crítica, o segundo filme de Back foi praticamente desprezado pelo grande público. Com isso, Back ao mesmo tempo se endividou e se desiludiu com o público que, segundo ele, não estava interessado em filmes "sérios", preferindo o entretenimento fácil.

Como resultado, no período entre 1971 e 1975, endividado, Sylvio Back não teve condições de realizar nenhum novo longa-metragem, apesar de ter declarado diversas vezes que pretendia fazê-lo. Ao longo desses quatro anos, ele atuou no campo publicitário, que vinha se fortalecendo no país, inclusive em Curitiba, e que oferecia oportunidades de trabalho para diversos artistas e intelectuais. "Não tenho vergonha de dizer, fiz filmes de publicidade, porque me endividei com ‘A Guerra dos Pelados”' - explicava Back em 1975, mas sem esconder que esta atividade não lhe trazia satisfação pessoal, pois apesar do "lucro certo" - "há uma predominância da técnica sobre a preocupação artística" (In: DIRETA, 1975).

Após essa experiência, o discurso da comunicabilidade que marcara o ingresso de Back no campo cinematográfico, expresso no tempo de produção de Lance Maior, perdeu o sentido. Além do mais, a conquista do público (que a cada vez mais era entendido como "mercado", desde que o governo passou a investir numa política cultural para o cinema) vinha sendo caracterizada pela ascensão dos filmes de fácil assimilação e das pornochanchadas.

Os tempos pediam novos motes de discussão. E ao mesmo tempo em que o segundo filme de Back era desprezado pelo público, aparecia, na política cultural do governo federal, um crescente apelo ao nacionalismo. Isso coincide com a assunção da defesa de um cinema

\footnotetext{
${ }^{6}$ O roteiro do filme é baseado no romance Geração do Deserto, de Guido Wilmar Sassi, publicado em 1964.

${ }^{7}$ O Júri Nacional de Cinema que concedeu os prêmios do INC para os filmes lançados no ano de 1971 reuniu-se em 1972, coordenado por Armando Tróia (presidente do INC entre 1971-72) e era formado por: Carlos Maximiano, Clóvis Sena, Motta e Justino Martins, além dos outros críticos já citados que haviam escrito as seguintes matérias: AZEREDO, 1971; EWALD FILHO, 1969; BARROS, 1971; FERREIRA, 1971; SHATOVSKY, Alberto; AZEREDO, Ely; ANDRADE, Valério, 1968.
} 
voltado "às questões históricas e culturais do sul", na fala de Sylvio Back. Aos poucos, o discurso sobre o sul e sobre a representação da realidade brasileira a partir da ótica do sul substitui, nas declarações públicas do cineasta, o mote da comunicabilidade, e torna-se bastante forte ao tempo de produção e lançamento do Aleluia, Gretchen!. Ou seja, como veremos a seguir: justo o tempo em que a Política Nacional de Cultura (PNC) do governo Geisel insiste na valorização das peculiaridades regionais para a representação da nacionalidade.

Naquele tempo que separa $A$ Guerra dos Pelados do tempo de produção de Aleluia, Gretchen! (ou seja, entre 1971 e 1975), as relações entre os grupos produtores de cultura, a sociedade e o Estado foram se tornando cada vez mais complexas e, segundo Ortiz Ramos (1983, p.100), as antigas divergências ideológicas entre os grupos nacionalista e universalista cediam um lugar cada vez maior às preocupações com o mercado e com o público, "colocando-se o caráter industrial do cinema acima das aversões ideológicas".

A expansão dos meios de comunicação e do cinema favorecida pelo Estado criava novos espaços culturais, ocasionando novos relacionamentos entre grupos produtores, cineastas, sociedade e Estado (MICELI, 1984). A Embrafilme, que em seus primeiros tempos de atuação carecia de um delineamento mais claro da política implementada, aos poucos procurava assumir uma função mais planejada de financiamento, centrada nas preocupações comerciais mas, ao mesmo tempo, continuava estimulando a produção de filmes "culturais", conforme as propostas do MEC. Desse modo, ia sendo gestada, naqueles anos, uma política cultural em que a preocupação com o "nacionalismo" se transformava em ideologia de Estado. A idéia de um cinema "revolucionário" defendida pelos cinemanovistas na década anterior havia sido esmaecida dentro das posições ideológicas próximas ao tema da "união nacional".

De acordo com dados estatísticos fornecidos pela própria Embrafilme, o crescimento mais significativo do cinema brasileiro iria acontecer principalmente após 1974, tanto em matéria de produção quanto de arrecadação. Este período dourado da empresa coincide com a presença de Ernesto Geisel no governo federal e Ney Braga à frente do Ministério da Educação e Cultura. Geisel assumia o país num momento delicado, encontrando, de um lado, uma crise econômica e, de outro, a erosão da legitimidade do regime. Ensaiando uma estratégia de liberalização política, o governo Geisel propôs uma "distensão política", que fosse "lenta, gradual e segura", visando retornar a um tipo de democracia restrita e controlada. Em meio a todos os conflitos inerentes a esse processo político e econômico, o Estado continuaria a sua ação no âmbito cultural, fortalecendo o ideário nacionalista. Um dos seus objetivos era a busca de legitimação do seu programa de "distensão" junto aos formadores de opinião (jornalistas, artistas, intelectuais). E, de fato, alguns setores da esquerda nacionalista "vislumbraram elementos positivos nesta política cultural", como foi o caso, no cinema, de Nelson Pereira dos Santos e de Cacá Diegues, por exemplo, no 
momento em que a Embrafilme vivia a sua fase de maior vigor (RAMOS, 1983, p. 147-48).

À frente do Ministério de Educação, estava o político paranaense Ney Braga, que encomendou a elaboração de um documento no qual estivessem traçadas as diretrizes da Política Nacional de Cultura (PNC), publicada em forma de documento em 1975. Não se pode negar que aquele governo fora o que mais dedicara atenção ao cinema até então. Contudo, deve-se tentar entender o fomento cinematográfico do governo Geisel dentro do quadro geral de sua política cultural, principalmente porque o cinema não representava mais, como lembra Bernardet, o grande veículo popular que fora nos anos trinta ou quarenta, pouco atingindo as classes mais baixas - e talvez nem mesmo fosse assim um veículo tão importante para a construção e a sustentação de uma hegemonia ideológica do governo militar, como era, por exemplo, a televisão.

O ano de 1976 - ano de lançamento do Aleluia, Gretchen - marcou a consolidação de importantes modificações no âmbito das políticas em torno do cinema: o INC havia sido extinto no ano anterior, e em 1976 era finalmente criado o Conselho Nacional de Cinema (Concine), responsável pelas normas e fiscalização das atividades cinematográficas (AMÂNCIO, 2000, p.43-44). Além dessas mudanças, desde 1974 a Embrafilme operava também na coprodução, participando dos lucros resultantes do investimento nos filmes. E a presença do cineasta Roberto Farias na direção da empresa entre 1974-78 seria considerada produtiva no âmbito das negociações entre os interesses do Estado e os da classe cinematográfica (RAMOS, 1983, p.133).

Em 1975, Back apresentou o projeto de seu novo filme à Embrafilme e teve seu plano aprovado. Em maio de 1976, depois de dois meses de filmagens nas cidades de Curitiba e Blumenau, Aleluia, Gretchen! estava pronto. Em outubro do mesmo ano, com um custo aproximado de 1,2 milhões de cruzeiros cobertos em nível de co-produção por Sylvio Back e pela Embrafilme, o filme estreava em Curitiba e em Santa Catarina.

\section{A polêmica em torno de um filme que aborda o nazismo:}

\section{alegoria do seu tempo?}

Aleluia, Grethen! é um filme de ficção sobre uma família de imigrantes alemães (uma célula nazista) que se instalara no Sul do Brasil na década de 1930, e ali permanecera até os "dias de hoje" (ou seja, até a década de 1970, quando o filme foi realizado). Ao representar a passagem do tempo nessa família, o cineasta acabou por esquematizar e ironizar posições políticas por meio dos personagens (o liberal, o integralista, a nazista), enfatizando a ausência efetiva de transformações sociais. Seguindo a linha iniciada em Lance Maior, e presente também em $A$ Guerra dos Pelados, o tema de fundo no terceiro longa-metragem 
ficcional de Back é a permanência das estruturas sociais. Ao longo do filme, ninguém rompe sua condição de classe ou de poder, ninguém "progride" e ninguém promove modificações sociais, apesar da passagem do tempo, das mudanças conjunturais, e de alguns personagens expressarem verbalmente suas convicções revolucionárias. Estas, no entanto, só existem nas palavras. Na prática, o que reina é a acomodação.

Tal filme não teve uma receptividade "tranquila" como havia acontecido com o Lance Maior, pois acendeu polêmicas e causou impacto sobre a opinião pública. O tema do filme o nazismo no Brasil - era um tabu, e a forma como o cineasta trouxe-o à tona acendeu reações exacerbadas. Ele estava, afinal, ao lado dos nazistas ou contra eles? Este burburinho remonta ao $9^{\circ}$ Festival de Brasília, em 1976, coroando uma série de situações desagradáveis a Sylvio Back.

Back conta que àquela altura o filme ainda não havia sido submetido à censura, pois o Festival defendia que as obras chegassem incólumes ao público. De acordo com o cineasta, "o público na noite de sua exibição simplesmente pirou, delirava em aplausos. Mas nem tudo seriam flores", uma vez que o júri era presidido por Alberto Cavalcanti, e este, ao que consta, teria detestado a abordagem que foi dada ao tema no filme, classificando-a de "nostalgia nazi-fascista" (HABIB, 1977). ${ }^{8}$

Alguns jornais brasilienses registravam a presença de Aleluia, na ocasião da mostra competitiva, como um filme "animador", e "um dos mais esperados e comentados durante este Festival" (ARAÚJO, 1976). Mas a controvérsia sobre o seu conteúdo persistia: "O filme é a favor ou contra o nazismo?".

Para Back, parecia, estava claro que o Aleluia era uma alegoria crítica do pensamento autoritário, em especial no contexto do regime militar brasileiro. Tratando-se de um filme co-produzido por um órgão estatal, a situação toava paradoxal. Quando foi questionado sobre um possível cerceamento ideológico da Embrafilme, o cineasta se posicionou dizendo que a política cinematográfica daquela empresa não era monolítica e nem tinha objetivos de dirigismo estatal, que suas preocupações com o cinema eram antes "industriais" (BACK, 1976). Ao que parece, Back confiava na "neutralidade" desse órgão estatal, como acontecia com a maioria dos cineastas - inclusive os remanescentes do cinema novo - e isso é compreensível na medida em que a Embrafilme concretizava antigos desejos de estabelecimento de uma indústria cinematográfica assentada em capital nacional. E toda a polêmica em torno do filme de Back mostra, além disso, que a crítica velada ao governo militar não representava ameaça à estabilidade do regime em vigor, dada a forma alegórica da crítica. Aleluia era visto como um filme histórico, simplesmente, de modo parecido ao que

\footnotetext{
${ }^{8}$ Meses depois de encerrado o festival, contava-se que: “No Festival de Brasília do ano passado, enquanto Xica da Silva era definido como uma pornochanchada histórica, Aleluia, Gretchen recebia injustamente a acusação de 'nostalgia nazi-fascista' pelo presidente do júri, o cineasta octogenário Alberto Cavalcanti. Sussurrou-se, na época, que Cavalcanti prometeu fazer escândalo caso algum prêmio coubesse ao filme de Silvio Back" (HABIB, 1977)
} 
já acontecera com Os Inconfidentes (Joaquim Pedro de Andrade) e São Bernardo (Leon Hirszman), ambos de 1972.

No final das contas, toda a discussão gerada em torno do terceiro longa-metragem de Back teve um duplo efeito, pois trazia o seu nome para o rol dos cineastas "malditos", mas, ao mesmo tempo, chamava a atenção sobre ele. E se, como vimos, boa parcela do público demonstrou certa aversão ao filme, foi com ele que Back alcançou sua consagração no campo cinematográfico, especialmente quando a crítica passou a comentá-lo amplamente.

Em janeiro de 1977, por ocasião do Festival de Gramado, José Carlos Avellar escreveu um comentário para o Jornal do Brasil que é, na verdade, o primeiro texto de crítica cinematográfica voltado à análise dos recursos de expressão e da estrutura narrativa de Aleluia, Gretchen! Neste texto, Avellar comenta o estilo fragmentado da narração, a descontinuidade que resulta da estrutura em blocos e dificulta a interpretação do tempo diegético, bem como a composição da imagem que impede uma perfeita noção do espaço em que se desenvolve a ação. Alerta também sobre a forma de representação estilizada da história. $\mathrm{O}$ crítico, finalmente, olhava para o filme enquanto obra de arte em diálogo com seu tempo de produção.

Em março do mesmo ano, quando de sua participação no programa Perspectiva 77 na Cinemateca do Museu de Arte Moderna (MAM) do Rio de Janeiro e de sua pré-estréia naquela capital, o filme foi muito badalado, gerando opiniões controversas entre o público, a ponto de isso ser registrado na mídia. Vale a pena a descrição publicada no Última Hora:

Quinze dias atrás, no MAM, umas 150 pessoas voltaram da porta porque não havia mais lugar na sala de projeção [...]. Findo o filme, cuja exibição foi entremeada por risos e palmas, houve um debate de duas horas com o diretor [...]. Foi aí que as ideias sobre o significado de 'Aleluia, Gretchen' não encontraram um denominador comum. [...] A temperatura subiu mais ainda, no último sábado, no Cinema I, onde se viam filas uma hora antes do início da sessão. Pela primeira vez, na história daquela casa de espetáculos, foi batido o recorde de bilheteria. Era um filme brasileiro. Novamente, a plateia tinha, em sua maioria, jovens, que aliás não desistiram de entrar quando se anunciou que só havia lugar no chão. Os corredores do cinema ficaram intransitáveis. À saída da sessão, as impressões se agitavam desencontradas: é um filme ou uma charada? Outros: trata-se de um filme incoerente, sem pé nem cabeça. A maioria: gostei muito [...] mas não tenho opinião formada agora, preciso pensar em casa, ou 'o filme me fundiu a cuca'. E madrugada adentro foi só o que se ouviu: intermináveis discussões nos bares da Zona Sul (Carlos Vereza, um dos principais atores do filme, praticamente não conseguiu jantar, assediado por espectadores ansiosos para discutir o filme e o seu papel). (ALMADA, 1977).

Poucos meses depois, o Jornal de Brasília alegaria que os problemas de aceitação de Aleluia se deviam

ao fato de se tratar de um filme eminentemente político, coisa rara nas 
produções brasileiras desde 1968. Os que chegaram a ver o filme sem cortes, antes de seu lançamento, acharam-se no direito de profetizar: 'Não vai passar pela censura'. Felizmente, poucas cenas foram tesouradas, e não prejudicaram sua leitura. (HABIB, 1977).

Sérgio Habib, assim, aproveitava para lastimar o esvaziamento político do cinema nacional. Exatamente no mesmo dia da publicação desse texto de Habib, saía uma matéria em O Estado de São Paulo (1977) comentando os "problemas de aceitação" do filme:

'Fascista. Esse Back é um nostálgico do nazismo'. O comentário, à saída do Cine Rio - na segunda-feira de estreia do filme 'Aleluia, Gretchen' trouxe a São Paulo a assertiva central de uma confusa polêmica despertada pela fita entre o público de outras cidades, que a exibem há algumas semanas. Uma discussão que os críticos não endossam, mas que já manteve o diretor Sílvio Back debatendo durante horas com espectadores das sessões de pré-estréia - como no caso da apresentação feita no Museu de Arte Moderna do Rio. E que o levou à conclusão de estar diante de uma manifestação provocada por um fator bem definido: o esvaziamento político do cinema nacional. Há, para Back, uma distorção de ponto de vista entre as pessoas do público na medida em que elas passam a duvidar da própria mensagem traduzida por 'Aleluia, Gretchen'. 'As pessoas parecem não acreditar no que vêem. Não imaginam que um cineasta pode estar fazendo referências tão dirigidas. $O$ filme é transparente, translúcido. E se ele não é claro - já que é estruturado em diálogos, que não permitem uma 'leitura' imediata - tem, pelo menos, uma direção definida. É aí que as pessoas se confundem, e passam a inverter os valores: dizem que o filme é fascista. E no entanto, ele contém uma crítica feroz aos regimes totalitários, especificamente o getulista. ${ }^{9}$

Enfim, quando Aleluia estrelava nas salas de várias capitais brasileiras, entre março e junho de 1977, constitui-se em foco de interesse da mídia. A fortuna crítica desse filme superou significativamente a dos seus filmes anteriores, incluindo textos de críticos renomados como Jean-Claude Bernardet, Sérgio Augusto, Orlando Fassoni, Miguel Pereira, Pola Vartuck, além do já citado José Carlos Avellar, entre outros.

Certamente que o filme não agradou a todos, mas foi alvo de atenção, e tocava em questões importantes do momento em que foi produzido. Na Folha de São Paulo, jornal que se destacava como um dos mais ativos da oposição civil, Orlando Fassoni (1977) dizia:

O filme 'Aleluia, Gretchen', esse caleidoscópio de contradições, tem a seu favor o fato de ser um dos raros trabalhos preocupados com a revisão de fatos onde poucos têm a coragem de meter o nariz. Há até quem ache que Back, ao falar sinuosamente da infiltração nazi-fascista no Sul, foi mexer num vespeiro. Vespeiro ou não, o filme nos faz sentir, nessa época intensamente pobre e vazia para o cinema de ideias, que ainda existem autores preocupados em levantar questões que, sepultadas pelo tempo, prosseguem inspirando temores.

\footnotetext{
9 “Aleluia" provoca polêmica. O Estado de São Paulo, 25 mai. 1977. O mesmo texto foi reproduzido em: ÁLVARES, 1977. Sobre as diferentes reações do público, ver também: ANJOS, 1977.
} 
E nem se tratava apenas de levantar questões sepultadas pelo tempo, pois o filme constituía-se, em primeira instância, de uma alegoria crítica ao seu momento presente. Falar das relações autoritárias, da intolerância entre diferentes visões políticas, representar a tortura, eram todas questões bem atuais quando o filme foi colocado ao juízo do público e da crítica.

Nas páginas na revista Isto $\hat{E}$, Sérgio Augusto (que também escrevera matéria sobre Aleluia no mais famoso jornal alternativo da época, o Pasquim) apontava alguns pontos fracos do filme, mas também opinava a favor da sua importância:

Certo tipo de espectador, condicionado pela exuberância de Xica da Silva e a assepsia de Dona Flor e seus dois maridos, poderá afligir-se com a narrativa fragmentada e descontínua de Aleluia, Gretchen. Outras ressalvas serão feitas à má distribuição de talento entre os atores e ao tom falsete da dublagem. Nada disso, porém, impede que este terceiro longa-metragem do catarinense Sílvio Back [...] não deva ser acatado como o filme brasileiro mais polêmico desde A Guerra Conjugal, de Joaquim Pedro de Andrade, ou um dos mais polêmicos desde Terra em Transe, de Glauber Rocha. Ou, ainda, a mais instigante tentativa de imersão em nosso passado histórico desde Os Inconfidentes, também de Joaquim Pedro. (AUGUSTO, 1977, p. 38)..$^{10}$

Situando o filme de Back entre outras produções do cinema nacional que lhe eram contemporâneas, o comentário alerta sobre uma estetização do filme brasileiro que vinha ocorrendo paralelamente à cooptação pelo mercado, a exemplo de Xica da Silva e de Dona Flor e seus dois maridos (Bruno Barreto), ambos considerados "ecos do ideário da PNC" por Ortiz Ramos (1983, p. 132) ${ }^{11}$, e aproxima o Aleluia de outros filmes nacionais que tiveram, em anos próximos, um teor mais denso, experimental e crítico ${ }^{12}$. Dentro de um quadro em que se tornava evidente um esvaziamento político do cinema brasileiro, inclusive, as cobranças as investidas contra a "exuberância" de Xica da Silva, levaram Cacá Diegues (1978) a

\footnotetext{
${ }^{10}$ Dos filmes citados por Sérgio Augusto, Terra em Transe é o mais antigo, datado de 1967. Mas Os Inconfidentes é de 1972, e Guerra Conjugal é de 1975, tendo recebido, inclusive, prêmios de direção, atriz (Elza Gomes) e montagem no $8^{\circ}$ Festival de Brasília do Cinema Brasileiro. Note-se que foi baseado em livro homônimo, escrito pelo curitibano Dalton Trevisan, que também escreveu os diálogos para o filme.

${ }^{11}$ O filme Dona Flor e seus dois maridos (1976) foi um fenômeno de bilheteria, com quase dez milhões de espectadores. Os discursos de Bruno Barreto e de seu pai, o produtor Luís Carlos Barreto, aproximavam-se muito do ideário do governo militar, quando defendiam um cinema que fosse "elemento de integração nacional" e que "preservasse a identidade cultural brasileira, costumes e hábitos do povo" (RAMOS, 1983, p. 112 e 139). Bernardet (1978, p. 92-93) definia essas superproduções como "cinemão", associando-as à tendência de monopolização da indústria cinematográfica que era coerente com o modelo econômico seguido pelo regime militar. De acordo com Marcos Napolitano, os filmes Xica da Silva e Dona Flor e seus dois maridos seriam os principais referenciais do cinema brasileiro daqueles anos. "Mesclando humor, comédia, erotismo e figurinos luxuosos, ao retratar duas mulheres singulares, esses filmes tornaram-se grandes sucessos de bilheteria até pelo fato de sugerirem uma abordagem mais leve da história, dos problemas e dos costumes brasileiros". (NAPOLITANO, 2001, p. 116).

${ }^{12}$ Ainda segundo Napolitano (2001, p. 117), o Aleluia, Gretchen, que também foi um sucesso de crítica naquela ocasião, "propunha um caminho mais polêmico e crítico [...]. O filme aludia ao autoritarismo do regime militar, metaforicamente representado na cena final, quando os nazistas, com os uniformes negros da SS, dançam ao som de um samba".
} 
denunciar o cerceamento que vinha sofrendo por parte de uma "patrulha ideológica" de esquerda. ${ }^{13}$

O que importa reter acerca daquele momento de crescente ingerência estatal no meio cinematográfico, é que culminou na fragmentação dos interesses e projetos dos cineastas atuantes no país. Tornou-se até mesmo difícil definir, dentro da historiografia já traçada sobre o cinema nacional, a existência de objetivos comuns àqueles cineastas. Ortiz Ramos dá ênfase ao crescimento quantitativo da produção entre 1974-78, mas descreve o seguinte mapa de relações:

\begin{abstract}
Complexidade e fragmentação no interior do cinema brasileiro, agregadas à possibilidade de finalmente configurar-se uma indústria cultural no setor, vão compor este quadro em que as rachaduras se multiplicarão, num entrelaçamento de conflitos que abrangem desde interesses de grupos, até concepções distintas do processo cultural cinematográfico. Todo burburinho que envolve a sucessão da Embrafilme e Concine, indica a alta temperatura política de um momento, em que à multiplicidade de propostas e pontos de vista culturais alia-se uma resistência, ou quem sabe desinteresse e incapacidade, diante da formulação de projetos totalizantes, quer políticos, quer culturais e estéticos (RAMOS, 1983, p.147).
\end{abstract}

Com o teor político de Aleluia, Gretchen! Back consegue recuperar um aspecto importante do cinema brasileiro que parecia desgastado. Mas, ao mesmo tempo, deslizava junto às discussões identitárias que se processavam nesse espaço de tensões entre cinema e política estatal.

\title{
4. Sylvio Back nas tensões entre o regional, o nacional e a Política Nacional de Cultura
}

Enfim, um último ponto a destacar neste texto diz respeito às relações entre o "regional" e a representação do nacional no cinema brasileiro daqueles anos, e o modo como isso está tensionado no seu terceiro filme e nas declarações de Back.

Ao mesmo tempo em que o "nacionalismo" convertia-se em ideologia justificativa da indústria cultural, havia, por parte do governo federal, a preocupação em preservar peculiaridades das culturas regionais frente às sequelas motoniveladoras desta mesma indústria. Tal preocupação ganharia força oficial sobretudo por volta de 1975, quando Ney Braga estava a frente do MEC, e após o lançamento da Política Nacional de Cultura (PNC)

\footnotetext{
${ }^{13}$ Em vários outros momentos Cacá Diegues se referia a essa "patrulha ideológica", em textos que foram posteriormente reunidos em: DIEGUES, 1999 [ver páginas: 25, 33, 43 e 46].
} 
encomendada por ele no ano anterior. A ideia de "identidade nacional", neste documento, estava vinculada à noção de "identidade do homem brasileiro". Através destas noções, procuravam-se maneiras possíveis de se operar com a diversidade interna da cultura brasileira. Próximo à estreia de Aleluia, e conforme ia ocorrendo o lançamento do filme em diferentes Estados - ou seja, no período entre 1975-77 - se tornou recorrente referir-se à obra de Back como "trilogia do sul", sendo que a mídia ia na esteira das declarações do cineasta ${ }^{14}$. Mas certas afirmações que foram feitas, talvez apressadamente em meio à euforia da divulgação do filme, arriscavam vincular uma imagem "regionalista" ao diretor. Isso poderia encurtar o alcance de significados dos seus filmes a aspectos culturais restritos aos estados meridionais, sem validade para outros locais. O que seria capaz, não é de se duvidar, de comprometer a aceitação do Aleluia, Gretchen! em outras regiões brasileiras, ao conferir um aspecto exótico ao filme, como se este "desconhecido homem do sul" se tornasse o Outro ante os olhos de um público acostumado a ver, como representante do "povo brasileiro", a face, o sotaque e os hábitos culturais do nordestino.

Aparentemente cuidadoso com este risco, Sylvio Back, ao mesmo tempo em que reiterava a sua trilogia sulina, empenhava-se na divulgação de que a sua proposta, neste filme, consistia em "incorporar a saga dos imigrantes alemães na revelação do homem brasileiro". Em entrevista ao jornal Opinião (1977), explicava que o "Aleluia, Gretchen é a procura de uma identidade [...]. Por que nós brasileiros somos assim?”. Ou seja, Back responde às menções regionalistas sobre seu filme com a proposta de acrescentar dados da história sulina para enriquecer o estudo do "tipo brasileiro". Mas, como a divulgação do filme reforçava que o tema era a imigração alemã, específica da região Sul, as expectativas poderiam facilmente recair sobre "as contribuições da cultura alemã", no sentido folclorizado com que até hoje nos habituamos a tratar deste assunto. Por isso, nas entrevistas que concedia à mídia, Back também se esforçava por quebrar esta impressão errônea, e explicava que, mesmo estando pautado sobre uma característica histórica da região Sul, nem por isso o filme rescinde ao lado folclórico da imigração alemã. "Ela se impõe, isso sim, como um vigoroso pano de fundo, misturado aos acontecimentos políticos brasileiros das últimas décadas, onde se movem os personagens para cuja compreensão exige-se a plena participação do público espectador" (BACK, apud ARAÚJO, 1976). Colocações desse teor buscavam alargar as margens para a interpretação de Aleluia, Gretchen! como um filme cuja abrangência era de alcance nacional. A questão, segundo discursava Back, era falar do "brasileiro", de suas origens - onde se incluía obrigatoriamente o fenômeno imigratório -, e dos acontecimentos políticos do Brasil.

Todavia, a afirmação de Back de que pretendia contribuir na "revelação do homem brasileiro", não brotava de solo imaculado. O seu simples enunciado carregava toda uma séria de antecedentes nos debates culturais brasileiros e, naquele momento imediato,

${ }^{14}$ Desde o tempo de preparação do roteiro de Aleluia, Gretchen!, Back passou a declarar publicamente que, com esse terceiro filme de ficção, estaria completando uma "trilogia sobre o Sul" do Brasil. 
parecia comportar até mesmo uma carga estrategicamente "diplomática" frente à visão oficial da PNC, capaz de gerar um efeito publicitário positivo. Também não era uma afirmação inédita, pois fazia parte de uma declaração do cineasta que já havia sido publicado no ano anterior no caderno cultural Anexo, do jornal Diário do Paraná (1976), e que também seria reproduzido em 1978, num dossiê crítico sobre o Aleluia veiculado pela revista Filme Cultura.

O depoimento inicia nos seguintes termos:

\begin{abstract}
Incorporar a saga dos imigrantes alemães à revelação do homem brasileiro, eis o desafio a que me propus em termos cinematográficos. É uma ideia antiga, fruto da minha origem étnica, e amadurecida ante a necessidade de recuperar um patrimônio cultural já em fase de diluição.

Natural da região Sul, desde Lance Maior - uma espécie de crônica pessoal mesclada a uma visão da alienação dos jovens da província - e confluindo para $A$ Guerra dos Pelados - o avesso ou o lado escuro da História do Brasil - sempre permaneci às rebarbas do problema básico da civilização meridional: os imigrantes. Com Aleluia, Gretchen resgatei essa lacuna, e surgiu uma trilogia que não fora premeditada, mas que, ao longo dos percalços e imponderabilidade do cinema brasileiro, acabou existindo. (Filme Cultura, 1978).
\end{abstract}

Quando menciona um "patrimônio cultural já em fase de diluição", Back parece ter incorporado ao seu discurso - que na década anterior centralizava-se na urgência em comentar a realidade social do "seu tempo" - o anseio por resgatar e conferir memória a alguma coisa que corria o risco de se perder. Algo que teria sido original num determinado ponto do tempo e do espaço no passado brasileiro, e que agora arriscava ser diluído pela modernização avassaladora e seus meios de comunicação homogeneizadores. Por essa ótica, como se vê, existiria íntima relação entre o projeto de Back e as preocupações com a preservação da diversidade regional contidas no PNC. Diversidade, é claro, que seria mantida desde que a coexistência das diferenças ocorresse de forma pacífica, dentro dos interesses governamentais de controle da Unidade Federal. E o epílogo de Aleluia, aquele piquenique onde todos dançam uma música que sincretiza rock, batucada e Wagner, surge como uma imagem possível desta coexistência pacífica. Só que ali, a crítica se disfarça com as vestes da ironia.

Ser irônico é uma das formas de enunciação crítica. Este é um aspecto retórico reconhecível no conjunto desses três filmes ficcionais de Back, produzidos entre 1968 e 1976. Em Aleluia, Gretchen!, especialmente, as referências ao Brasil são mais irônicas do que celebrativas, e referem-se alegoricamente ao seu presente imediato, antes mesmo do que às minúcias históricas do passado representado. Através da moldagem de personagens que esquematizam posturas políticas as mais variadas; todas coexistindo e, ao final, conformando-se mutuamente, como os personagens que esquematizam as classes sociais 
brasileiras - Repo (o povo) assimila a ideologia de seu patrão, e Eurico (a classe média) sustenta os seus opressores - se "conformam" à situação. No conjunto, o resultado (ou a pretensão) é a descrição de um "painel do Brasil", para usar uma expressão do crítico José Carlos Monteiro (1977) sobre o filme, cuja síntese na cena do piquenique funciona como uma charge do mesmo "sincretismo" que era enunciado como desejável pelo PNC em 1975. Uma situação onde todos coexistem pacificamente, onde os conflitos são abafados e as lutas de classes silenciadas, como era de interesse do governo em vigor.

Para concluir, vale ressaltar que após a série de polêmicas em torno da ambiguidade do Aleluia, o discurso "sulino" de Back sobre o seu próprio cinema foi enfraquecendo e, gradualmente, passou a dar lugar ao discurso do "autor" comprometido unicamente com a estética cinematográfica. Nesse momento, fica claro que os interlocutores que Back busca já não estão diluídos num amplo "público virtual" (a procura de comunicação com o público, tão cara no início de sua carreira), mas constituem-se, antes, dos seus pares no meio cinematográfico e de sua vontade de inserção nesse âmbito da cultura brasileira, em constantes negociações com os interesses políticos do estado.

\section{Bibliografia e fontes documentais:}

A Aleluia de Sílvio. Direta. Curitiba, 15 nov. 1975.

A civilização do Sul: o essencial é ser autêntico. Entrevista com Sílvio Back. Opinião. $1^{\circ}$ abr. 1977.

Aleluia, Gretchen. Anexo. Diário do Paraná. Curitiba, 24 ago. 1976.

Aleluia, Gretchen: a favor ou contra o nazismo? Jornal do V Festival de Cinema Brasileiro de Gramado, 17 a 22 de jan. 1977.

Aleluia, Gretchen. Dossiês críticos. Filme Cultura, n³0. Rio de Janeiro: INC, ago. 1978, p.91-97.

“Aleluia" provoca polêmica. O Estado de São Paulo, 25 mai. 1977.

ALMADA, Teresa. Aleluia, Gretchen. Última Hora. Rio de Janeiro, 31 mar. 1977.

ÁLVARES, Luzia Miranda. “Aleluia, Gretchen": polêmica em S. Paulo. O Liberal. Belém, 27. mai. 1977.

AMÂNCIO, Tunico. Artes e Manhas da Embrafilme: Cinema Estatal Brasileiro em Sua Época de Ouro (1977-1981). Niterói: EdUFF, 2000.

ANJOS, Edvaldo dos. A polêmica de volta ao cinema brasileiro com "Aleluia, Gretchen". A Gazeta. Vitória, 4 mai. 1977. 
ARAÚJO, Celso. Os “Kranz” num piquenique alemão. Correio Braziliense. Brasília, 25 jul. 1976.

Arte: assunto de interesse do governo. Entrevista com Jarbas Passarinho. Jornal da Tarde. São Paulo, 10 set. 1970.

AUGUSTO, Sérgio. Como é mesmo anauê em alemão? Isto é, 6 abr. 1977.

AVELLAR, José Carlos. Aleluia, Gretchen: o rosto sempre igual da violência. Jornal do Brasil, Rio de Janeiro, 29 jan. 1977.

AZEREDO, Ely. “Lance Maior”. Jornal do Brasil. Rio de Janeiro, 15 dez.1968.

AZEREDO, Ely. “A guerra dos pelados” (I). Jornal do Brasil. Rio de Janeiro, 30 set. 1971.

AZEREDO, Ely. “A guerra dos pelados” (II). Jornal do Brasil. Rio de Janeiro, 3 out. 1971.

BACK, Sylvio. "Aleluia, Gretchen", uma película destinada a causar muita polêmica. Entrevista concedida a G. T. Nunes. Diário de Brasília. 23 jul. 1976.

BACK, Sylvio. No cinema, embustes e verdades da história. Entrevista a Cesar Bond, José Roberto Guidali e Telma Serur. O Estado do Paraná. Curitiba, 20 abr. 1979.

BACK, Sylvio. Entrevista a Adélia Lopes e Dante Mendonça. O Estado do Paraná, 24 abr. 1988.

BACK, Sylvio. Entrevista concedida à autora por telefone, em $1^{\circ} .09 .2003$.

BACK, Sylvio. Depoimento concedido à autora em 16 fev. 2007, por e-mail.

BARROS, Luiz Alipio de. A Guerra dos Pelados. Última Hora. Rio de Janeiro, 30 set. 1971.

BERNARDET, Jean-Claude. Cinema brasileiro: propostas para uma história. Rio de Janeiro: Paz e Terra, 1979.

BIÁFORA, Rubem. Lance Maior. O Estado de São Paulo. 2 mar. 1969.

CAPARELLI, Sergio. Comunicação de massa sem massa. São Paulo: Cortez, 1980.

Cinema brasileiro: cinco novos filmes. Filme Cultura n $^{\circ 11}$. Rio de Janeiro: INC, nov. 1968.

CONTIER, Arnaldo. "Ainda existe o elitismo no cinema nacional". Os anos 70. Folhetim. São Paulo, 16 dez. 1979.

DIEGUES, Carlos. Quero um cinema de muitas faces, um cinema popular. Entrevista concedida a Pola Vartuck. O Estado de São Paulo, 31 ago. 1978.

. Cinema brasileiro: idéias e imagens. Porto Alegre: UFRGS/ MEC/ SESu/ PROED, 1999.

DREIFUSS, René e DULCI, Otávio. As forças armadas e a política. In: SORJ, Bernardo e ALMEIDA, Maria Hermínia. Sociedade e política no Brasil pós-64. São Paulo: Brasiliense, 1983.

EWALD FILHO, Rubens. Silvio Back, o homem (1). A Tribuna. Santos, 14 mar. 1969 
FASSONI, Orlando. O nazismo, no sul do Brasil. Folha de São Paulo. São Paulo: 2 jun. 1977.

FERREIRA, Fernando. A guerra dos pelados contra os peludos. $O$ Globo. Rio de Janeiro, 30 set. 1971.

HABIB, Sérgio. Batucada wagneriana. Jornal de Brasília, 25 mai. 1977.

MICELI, Sérgio. Estado e cultura no Brasil. São Paulo: Difel, 1984.

-------. O papel político dos meios de comunicação de massa. In: SCHWARTZ, Jorge; SOSNOWSKI, Saúl (orgs.). O trânsito da memória. São Paulo: EDUSP, 1994.

MONTEIRO, José Carlos. Aleluia, Gretchen. O Globo. Rio de Janeiro: 2 abr. 1977.

NAPOLITANO, Marcos. Cultura brasileira: utopia e massificação (1950-1980). São Paulo: contexto, 2001.

ORTIZ, Renato. A moderna tradição brasileira. São Paulo: Brasiliense, 1988.

RAMOS, José Mário Ortiz. Cinema, estado e lutas culturais: anos 50/60/70. Rio de Janeiro: Paz e Terra, 1983.

RIDENTI, Marcelo. Em busca do povo brasileiro: artistas da revolução, do CPC à era da tv. Rio de Janeiro; Record, 2000.

SCHWARZ, Roberto. Cultura e política. São Paulo: Paz e Terra, 2001.

SHATOVSKY, Alberto; AZEREDO, Ely; ANDRADE, Valério. O filme em questão: Lance maior. Jornal do Brasil, Rio de Janeiro, 21 dez.1968.

Silvio Back na "Guerra dos Pelados". Filme Cultura, n¹6. Rio de Janeiro, INC, set/out. 1970.

SOARES, Gláucio e D'ARAÚJO, Maria Celina (orgs). 21 anos de regime militar: balanços e perspectivas. Rio de Janeiro: FGV, 1994. 